\title{
Alocação de íons e crescimento de plantas de cajueiro anão-precoce irrigadas com água salina no campo ${ }^{1}$
}

\author{
Laíse F. de Araújo ${ }^{2}$, Reivany E. M. Lima ${ }^{3}$, Léa de O. da Costa ${ }^{4}$, \\ Ênio M. de C. Silveira ${ }^{5}$ \& Marlos A. Bezerra ${ }^{6}$ \\ ${ }^{1}$ Trabalho selecionado do II INOVAGRI International Meeting, realizado de 13 a 16 de abril de 2014, Fortaleza - CE, Brasil \\ ${ }^{2}$ DENA/UFC. Fortaleza, CE. E-mail: laiseferreiradearaujo@gmail.com (Autor correspondente) \\ ${ }^{3}$ DENA/UFC. Fortaleza, CE. E-mail: reivany_eduardo@hotmail.com \\ ${ }^{4}$ UFC. Fortaleza, CE. E-mail: leacostaadv@yahoo.com.br \\ ${ }^{5}$ SDA. Fortaleza, CE. E-mail: enio2121@hotmail.com \\ ${ }^{6}$ Embrapa Agroindústria Tropical/INCTSal/CNPq. Fortaleza, CE. E-mail: marlos.bezerra@embrapa.br
}

\section{Palavras-chave:} Anacardium occidentale estresse salino

tolerância

\begin{abstract}
R E S U M O
São escassos estudos com salinidade em plantas adultas de cajueiro, dessa forma objetivou-se avaliar a acumulação de íons e o crescimento de plantas de cajueiro anão-precoce irrigadas com água salina. O experimento foi conduzido na Embrapa Agroindústria Tropical, em Pacajus, CE. Durante treze meses plantas do clone CCP 06 foram irrigadas com soluções salinas de diferentes condutividades elétricas $\left(0,4 ; 1,5 ; 3,0 ; 4,5\right.$ e $\left.6,0 \mathrm{dS} \mathrm{m}^{-1}\right)$, com os tratamentos dispostos em blocos ao acaso com três repetições. A irrigação foi feita por microaspersores e ao final as plantas foram coletadas e fracionadas em raízes absorventes (finas) e de sustentação (grossas), caule + ramos e folhas, para determinação dos teores de $\mathrm{Na}$ e $\mathrm{Cl}$ nesses órgãos, da área foliar e da massa da matéria seca dos órgãos aéreos. Os dados foram submetidos à análise de variância e de regressão pelo programa ASSISTAT. Para as variáveis Na no caule e na folha, houve efeito significativo entre os níveis de salinidade aplicados, apresentando médias de 3,0 e 6,0 mg $\mathrm{g}^{-1} \mathrm{MS}$ para a maior condutividade elétrica, respectivamente. Para o $\mathrm{Cl}$, diferenças foram observadas somente para as raízes de sustentação, com uma média de $4,8 \mathrm{mg} \mathrm{g}^{-1} \mathrm{MS}$ para a salinidade de $6,0 \mathrm{dS} \mathrm{m}^{-1}$. Entretanto, o acúmulo de sais nos órgãos das plantas não foi suficiente para afetar as variáveis de crescimento estudadas no cajueiro anãoprecoce, bem como não foi verificado danos visuais.
\end{abstract}

Key words:

Anacardium occidentale salt stress

tolerance

\section{Allocation of ions and growth dwarf cashew plants irrigated with saline water}

\begin{abstract}
A B S T R A C T
There are few studies on effects of salinity on adult cashew plants, thus the objective was to evaluate the growth and ion accumulation in dwarf cashew plants, irrigated with saline water. The experiment was conducted at Embrapa Agroindústria Tropical, in Pacajus, CE. For thirteen months the treatments in seedlings of clone CCP 06 were applied. The treatments were arranged in a randomized block design with three replications, referring to salt solutions adjusted to different electrical conductivities $\left(0.4,1.5,3.0,4.5\right.$ and $\left.6.0 \mathrm{dS} \mathrm{m}^{-1}\right)$. The plants were irrigated by microsprinkler system and were collected and divided into absorbing roots (thin) and support (thick), stem + branches and leaves, to determine the levels of $\mathrm{Na}$ and $\mathrm{Cl}$ in these organs, leaf area and dry mass of aerial parts. Data were subjected to analysis of variance and regression by ASSISTAT program. As for the variables Na in the stem and leaf, significant effects of salinity levels, with averages of 3.0 and $6.0 \mathrm{mg} \mathrm{g}^{-1} \mathrm{DM}$ for the highest level of electrical conductivity applied, respectively. Regarding $\mathrm{Cl}$, statistical differences were noted only for the support roots, with an average of $4.8 \mathrm{mg} \mathrm{g}^{-1} \mathrm{DM}$ for salinity of $6.0 \mathrm{dS} \mathrm{m}^{-1}$. However, the accumulation of salts in plant organs was not enough to affect the growth variables studied in dwarf cashew.
\end{abstract}

\section{INTRODUÇÃ̃o}

O estresse salino pode inibir o crescimento das plantas, por reduzir o potencial osmótico da solução do solo e consequentemente o potencial hídrico, restringindo a disponibilidade de água, além de provocar acumulação excessiva de íons nos tecidos vegetais, podendo causar toxicidade iônica, desequilíbrio nutricional, ou ambos (Silva et al., 2008).
Os danos às plantas ocorrem quando os íons tóxicos são absorvidos em quantidades significativas, junto com a água absorvida pelas raízes, as quais ultrapassam a capacidade da planta de compartimentalizá-los no vacúolo. Consequentemente, a concentração de sais aumenta no citoplasma e inibe a atividade de enzimas de várias rotas metabólicas (Prisco \& Gomes Filho, 2010). Além disso, o acúmulo de sais desencadeia a produção de espécies reativas de oxigênio, compostos responsáveis pelo 
estresse oxidativo. Todos esses processos causam uma redução no crescimento das plantas, com consequente diminuição na produtividade das culturas (Soares \& Machado, 2007).

Para suportar o estresse salino, muitas plantas acumulam solutos orgânicos no citosol e/ou íons inorgânicos no vacúolo, os quais baixam o potencial osmótico, num mecanismo conhecido como ajustamento osmótico (Meloni et al., 2004), proporcionando absorção de água pela planta. Com isso, há um aumento no potencial de turgescência, exercendo importante papel no crescimento vegetal mediante a intensificação do alongamento celular.

No entanto, o grau de severidade com que cada um desses componentes influencia o crescimento e o desenvolvimento das plantas é dependente de muitos fatores, dentre eles, podese citar: a tolerância da espécie ou cultivar vegetal, o estádio fenológico, a composição salina do meio, a intensidade e duração do estresse, bem como das condições edafoclimáticas e o manejo da irrigação (Gheyi et al., 2005).

No Brasil, embora a informação sobre as áreas salinas não seja bem precisa, estima-se que 20 a $25 \%$ das áreas irrigadas enfrentem problemas de salinização (FAO, 2006). Considerando que a prática da irrigação constitui a única maneira de garantir a produção agrícola com segurança no semiárido e que a implantação dos projetos de irrigação tem sido incrementada nas últimas décadas, configura-se como de grande importância para a produção agrícola nessa região brasileira o desenvolvimento de pesquisas que venham a possibilitar um melhor manejo do solo e da água, face às projeções futuras de aumento da população e da demanda por alimentos.

No semiárido nordestino, o cajueiro (Anacardium occidentale L.) é uma espécie amplamente cultivada, se apresentando como uma cultura importante na geração de emprego e renda. A expansão da cajucultura nessas áreas está apoiada na utilização de clones de cajueiro anão-precoce. Entretanto, embora haja a oferta de vários clones adaptados a diferentes condições ambientais, basicamente se utiliza um único porta enxerto, o CCP 06 (Cavalcanti Junior et al., 2003), para o qual há carência de estudos da interação com o ambiente, especialmente em relação aos efeitos do estresse salino, que contribuem para redução do crescimento e da produtividade das plantas.

Neste sentido, objetivou-se avaliar o acúmulo de sais e o crescimento de plantas de cajueiro anão-precoce, clone CCP 06, cultivadas em campo, sob condições de estresse salino.

\section{Material e Métodos}

O experimento foi realizado no Campo Experimental de Pacajus, da Embrapa Agroindústria Tropical (4 10' S e 38²7' W), altitude de $60 \mathrm{~m}$. O clima é Aw segundo Köppen (clima tropical com inverno seco).

Os porta enxertos e os propágulos do clone CCP 06 de cajueiro anão-precoce foram oriundos de matrizes de cajueiro do Campo Experimental de Pacajus. As sementes foram colocadas em tubetes de $288 \mathrm{~cm}^{3}$, tendo como substrato uma mistura de casca de arroz carbonizada, bagana de carnaúba triturada e solo hidromórfico. A enxertia foi realizada aos 45 dias após o plantio das sementes e posteriormente as mudas do clone CCP 06, enxertadas sobre porta enxerto do próprio clone (para não haver interferência de outro porta enxerto), foram transplantadas para o campo (Neossolo Quartzarênico distrófico) com três meses de idade. A adubação foi feita por meio da incorporação de restolhos vegetais de feijão-caupi. Até o estabelecimento das mudas, as plantas receberam apenas água proveniente das chuvas (aproximadamente $1000 \mathrm{~mm}$ ). A partir daí o sistema de irrigação (microaspersores) foi instalado e aplicada água de poço $\left(0,4 \pm 0,2 \mathrm{dS} \mathrm{m}^{-1}\right)$ até as plantas estarem com 240 dias após o transplantio.

Aos 240 dias de transplantio das plântulas, iniciou-se a aplicação dos tratamentos, que consistiu da aplicação da irrigação, via microaspersão, das soluções salinas com

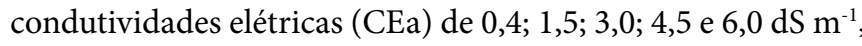
no período de novembro de 2011 a dezembro de 2012 .

A vazão média coletada dos aspersores foi de aproximadamente $50 \mathrm{~L} \mathrm{~h}^{-1} \mathrm{e}$ a irrigação foi realizada três vezes por semana, cada uma com duração de 30 min de aplicação de água. Essa lâmina aplicada baseou-se em Crisóstomo et al. (2003), que preconiza uma necessidade hídrica para o primeiro ano de estabelecimento de plantas de cajueiro anão-precoce na região litorânea do Ceará de 10 a $20 \mathrm{~L}$ diários por planta. Os tratamentos foram dispostos em blocos ao acaso, com três repetições. Cada parcela experimental foi composta por uma planta.

As soluções salinas foram preparadas pela adição de diferentes quantidades de sais de $\mathrm{NaCl}, \mathrm{CaCl}_{2} .2 \mathrm{H}_{2} \mathrm{O}$ e $\mathrm{MgCl}_{2} \cdot 6 \mathrm{H}_{2} \mathrm{O}$, na proporção equivalentes de 7:2:1, obedecendo-se a relação entre CEa e a concentração dos sais $\left(\mathrm{mmol}_{c} \mathrm{~L}^{-1}=\mathrm{CE}\right.$ x 10), extraída de Rhoades et al. (1992).

Ao final do período de aplicação dos sais, as plantas foram coletadas (Figura 1), fracionadas em raízes absorventes (finas), raízes de sustentação (grossas), caule + ramos e folhas. A área foliar foi quantificada utilizando um integrador de área foliar (LI-3100C, LI-COR) e os órgãos aéreos tiveram seus pesos da matéria seca mensurados, após secagem do material em estufa de circulação forçada de ar, a $70^{\circ} \mathrm{C}$. A matéria seca das raízes

A.

B.

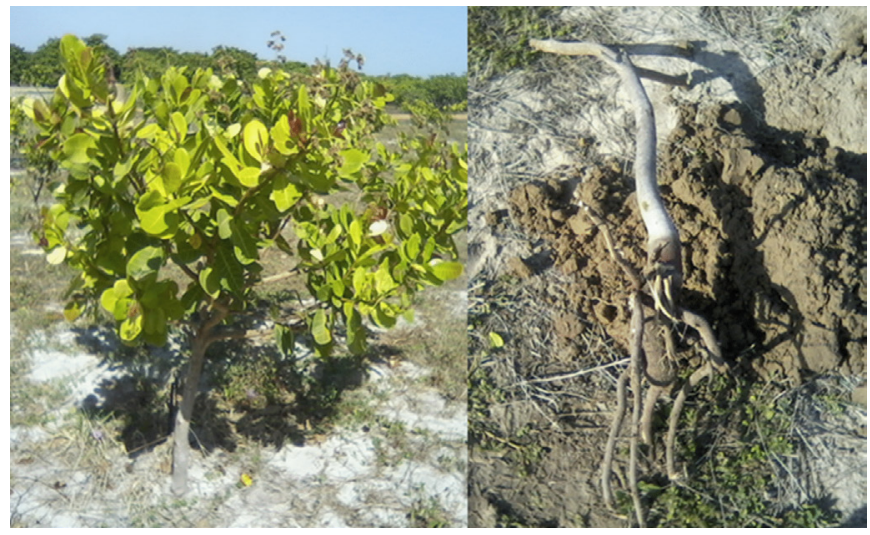

Figura 1. Planta de cajueiro anão-precoce após 13 meses de aplicação do tratamento com CEa de 4,5

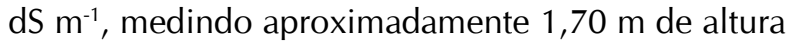
(A) e arranquio da planta para coleta das amostras (B) 
não foi mensurada devido a perda substancial de massa desse órgão, quando da extração das plantas de cajueiro anão-precoce.

Após a secagem, o material foi triturado em moinho, para a obtenção de um pó fino. Em seguida, 0,5 g desse material vegetal foi homogeneizado em $25 \mathrm{~mL}$ de água deionizada (passada através de filtros miliporos - mili-Q) e a mistura foi submetida à agitação por 2 horas, seguido de filtração em papel de filtro do tipo lento, sendo o filtrado armazenado em frascos e mantido refrigerado até o momento das determinações do $\mathrm{Na}^{+} \mathrm{e} \mathrm{Cl}$.

$\mathrm{O}$ teor de $\mathrm{Na}$ foi determinado no extrato por fotometria de chama (Malavolta et al., 1997). Para a determinação do $\mathrm{Cl}$, foram efetuadas leituras de absorbância a $460 \mathrm{~nm}$ em espectrofotômetro (Gaines et al., 1984).

Os tratamentos foram dispostos em um delineamento em blocos casualizados com três repetições. Os resultados foram submetidos à análise de variância e de regressão pelo programa ASSISTAT 7.6 beta.

\section{Resultados e Discussão}

Nos treze meses de condução do experimento choveu aproximadamente $500 \mathrm{~mm}$ (Figura 2), concentrados nos meses de fevereiro e março, $3^{\circ} \mathrm{e} 4^{\circ}$ mês do experimento, média muito baixa em relação à média histórica no município de Pacajus, que fica em torno de $950 \mathrm{~mm}$ (Aguiar et al., 2004), não havendo lixiviação dos sais no solo aplicados via irrigação.

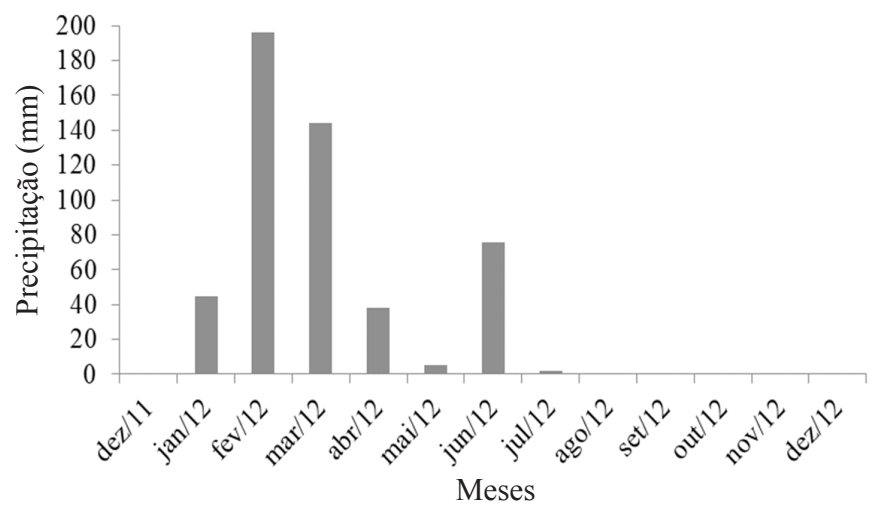

Figura 2. Precipitação ocorrida no Campo Experimental de Pacajus, durante os meses de novembro de 2011 a dezembro de 2012

Para o acúmulo de Na, houve efeito significativo apenas para o caule + ramos e para as folhas de plantas de cajueiro anão-precoce, não havendo efeito significativo nas raízes de sustentação (grossas) e nas raízes absorventes (finas) (Tabela 1).

A análise de regressão mostra um comportamento linear de acúmulo do sódio nos caules + ramos e nas folhas, com a tendência de acúmulo crescente com a elevação da salinidade do solo (Figura 3). A cada incremento de $1,0 \mathrm{dS} \mathrm{m}^{-1}$, há um aumento de 0,26 e 0,33 $\mathrm{mg} \mathrm{g}^{-1}$ de MS para o acúmulo de Na no caule + ramos e nas folhas, respectivamente. Quando os íons $\mathrm{Na}^{+}$ se acumulam em excesso nas folhas, pode ocorrer o surgimento de manchas necróticas e a queima de suas pontas (Bosco et al., 2009), sintomas não presenciados no presente trabalho, $o$ que sugere que até o nível máximo de salinidade utilizado $(6,0$
Tabela 1. Resumo de análise de variância para o $\mathrm{Na}$ ( $\left.\mathrm{mg} \mathrm{g}^{-1} \mathrm{MS}\right)$ na raiz grossa (NaRg), na raiz fina (NaRf), no caule + ramos $(\mathrm{NaC})$ e na folha $(\mathrm{NaF})$ de plantas do clone CCP 06 de cajueiro anão-precoce, irrigadas com águas de diferentes concentrações salinas, 13 meses após a aplicação dos tratamentos

\begin{tabular}{llllll}
\hline \multirow{2}{*}{ FV } & GL & \multicolumn{5}{c}{ Quadrados médios } \\
\cline { 3 - 6 } & & $\begin{array}{c}\text { Raiz grossa } \\
\text { (NaRg) }\end{array}$ & $\begin{array}{c}\text { Raiz fina } \\
\text { (NaRf) }\end{array}$ & $\begin{array}{c}\text { Caule } \\
\text { (NaC) }\end{array}$ & $\begin{array}{c}\text { Folha } \\
\text { (NaF) }\end{array}$ \\
Blocos & 2 & $0,05643 \mathrm{~ns}$ & $0,23088 \mathrm{~ns}$ & $0,13614 \mathrm{~ns}$ & $0,45515 \mathrm{~ns}$ \\
Tratamentos & 4 & $0,09605 \mathrm{~ns}$ & $1,06270 \mathrm{~ns}$ & $1,29733 *$ & $2,19319 *$ \\
Resíduo & 8 & 0,04792 & 0,36368 & 0,29264 & 0,57142 \\
Média & & 1,61 & 1,92 & 2,18 & 5,48 \\
CV (\%) & 13,54 & 31,43 & 24,72 & 13,80 \\
\hline
\end{tabular}

*,**: significativo a nivel de 0,05 e 0,01 de probabilidade, respectivamente, pelo teste $\mathrm{F}$; ns: não significativo.

dS $\mathrm{m}^{-1}$ ), o acúmulo de $\mathrm{Na}^{+}$nas plantas não causou danos aos diversos órgãos.

A suposição geral relacionada à tolerância ao $\mathrm{Na}^{+}$entre plantas e que elas compartimentalizam o $\mathrm{Na}^{+}$absorvido nos vacúolos e usam como um osmótico orgânico em lugar de ou em conjunto com o K+ (Greenway \& Osmond, 1972). O citosol das células nas plantas raramente tolera o $\mathrm{Na}^{+}$em níveis superiores de 20 mM (Wyn Jones, 1999), em que níveis altos de Na afetam a síntese protéica e a fosforilação oxidativa, como também a atividade de algumas enzimas, como a aspartato transaminase. A folha foi o órgão vegetal que mais acumulou o $\mathrm{Na}$ apesar das raízes estarem em contato direto com o solo irrigado com alta salinidade.

Em relação ao íon $\mathrm{Cl}$, houve efeito significativo apenas para as raízes de sustentação (grossas) (Tabela 2).

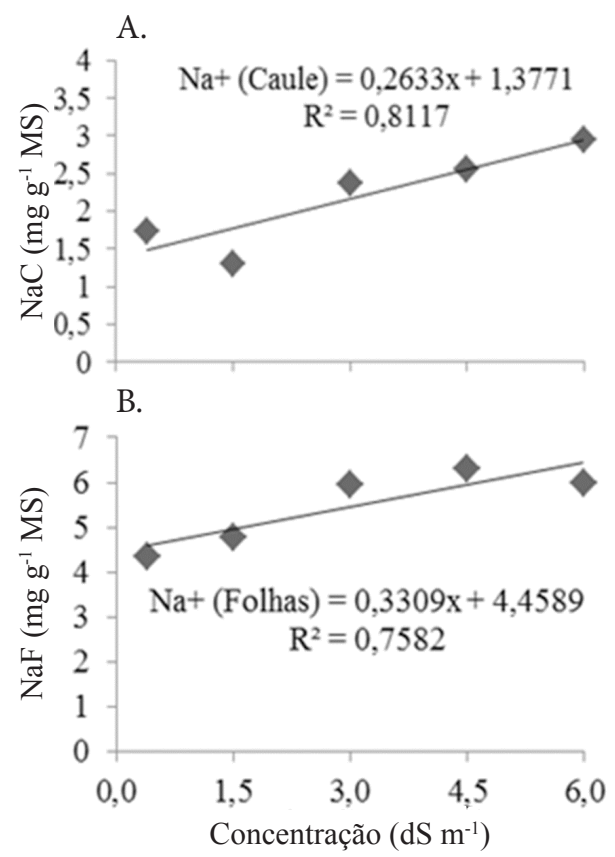

Figura 3. Teores de $\mathrm{Na}$ no caule $+\operatorname{ramos}(\mathrm{NaC})(\mathrm{A})$ e nas folhas $(\mathrm{NaF})(\mathrm{B})$ de plantas do clone CCP 06 de cajueiro anão-precoce, irrigadas com águas de diferentes concentrações salinas, 13 meses após a aplicação dos tratamentos 
Tabela 2. Teores de $\mathrm{Cl}\left(\mathrm{mg} \mathrm{g}^{-1} \mathrm{MS}\right)$ nas raízes grossas $(\mathrm{ClRg})$, ráizes finas $(\mathrm{ClRf})$, caule $+\operatorname{ramos}(\mathrm{ClC}) \mathrm{e}$ folhas (CIF) de plantas do clone CCP 06 de cajueiro anão-precoce, irrigadas com águas de diferentes concentrações salinas, 13 meses após a aplicação de tratamentos

\begin{tabular}{llllll}
\hline \multirow{2}{*}{ FV } & GL & \multicolumn{5}{c}{ Quadrados médios } \\
\cline { 3 - 6 } & & $\begin{array}{l}\text { Raiz grossa } \\
\text { (CIRg) }\end{array}$ & $\begin{array}{c}\text { Raiz fina } \\
\text { (CIRf) }\end{array}$ & $\begin{array}{c}\text { Caule } \\
\text { (CIC) }\end{array}$ & $\begin{array}{c}\text { Folha } \\
\text { (CIF) }\end{array}$ \\
Blocos & 2 & $0,32421 \mathrm{~ns}$ & $2,50962 \mathrm{~ns}$ & $0,45122 \mathrm{~ns}$ & $0,18639 \mathrm{~ns}$ \\
Tratamentos & 4 & $2,00265 *$ & $12,22741 \mathrm{~ns}$ & $1,42958 \mathrm{~ns}$ & $2,71687 \mathrm{~ns}$ \\
Resíduo & 8 & 0,48997 & 6,89818 & 1,39637 & 0,7978 \\
Média & & 3,78 & 10,82 & 5,9 & 5,22 \\
CV (\%) & 18,54 & 24,27 & 20,02 & 17,11 \\
\hline
\end{tabular}

${ }^{*}, * \star$ : significativo a nivel de 0,05 e $0,01 \%$ de probabilidade, respectivamente, pelo teste $\mathrm{F}$; ns: não significativo

A análise de regressão para o $\mathrm{Cl}$ nas raízes de sustentação apresentou um comportamento polinomial de segundo ordem, mostrando que o teor do íon sofre decréscimo inicialmente com a elevação da salinidade, seguido de aumento do acúmulo desse íon, de modo que no nível de salinidade mais alto $(6,0 \mathrm{dS}$ $\left.\mathrm{m}^{-1}\right)$, o teor fica praticamente semelhante ao das raízes controle (Figura 4).

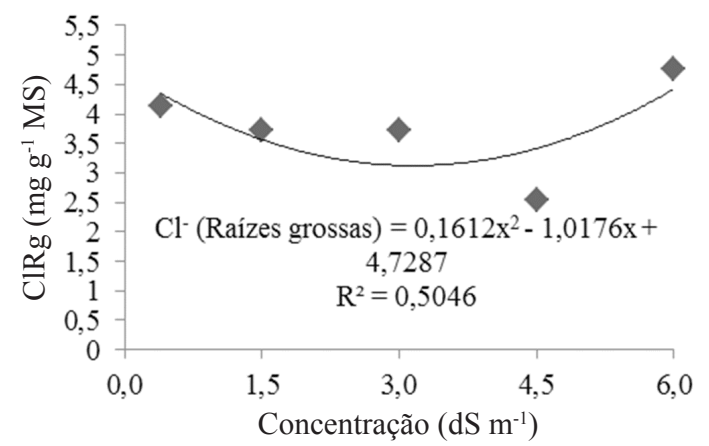

Figura 4. Teor de cloreto nas raíze (ClRg) de sustentação (grossas) (CIRg) de plantas do clone CCP 06 de cajueiro anão-precoce, irrigadas com águas de diferentes concentrações salinas, 13 meses após a aplicação de tratamentos

Em suma, o acúmulo de Na nos órgãos vegetais foi de 5,48; 2,18; 1,92 e 1,61 $\mathrm{mg} \mathrm{g}^{-1} \mathrm{MS}$ para as folhas, caule, raízes finas e raízes grossas, respectivamente. Já para o $\mathrm{Cl}$, foi de 10,82; 5,90; 5,22 e $3,78 \mathrm{mg} \mathrm{g}^{-1} \mathrm{MS}$ para as raízes finas, caule, folhas e raízes grossas, respectivamente. Logo, o acúmulo de $\mathrm{Cl}$ foi maior nas raízes absorventes, diferentemente do que aconteceu com o Na, em que o acúmulo foi maior nas folhas. Como o $\mathrm{Cl}$ foi aplicado em maior quantidade que o Na na água de irrigação, esperava-se que esse íon tivesse maior acúmulo nas partes da planta do que o $\mathrm{Na}$. No geral, os íons foram mais acumulados nas folhas e raízes, sendo essa acumulação menor no caule, similar ao encontrado por Ferreira et al. (2001), trabalhando com a cultura da goiabeira aplicando diferentes níveis de salinidade na fruteira. As raízes absorventes acumularam mais íons que as raízes de sustentação.

Segundo Willadino \& Camara (2010), as folhas são mais vulneráveis ao $\mathrm{Na}^{+} \mathrm{e} \mathrm{Cl}$ do que as raízes e o caule, simplesmente porque acumulam maiores concentrações desses íons, uma vez que ambos são transportados pela corrente transpiratória no xilema e se acumulam nas folhas quando a água é transpirada. Isso ocorreu no presente estudo, sendo que numa maior magnitude para o $\mathrm{Na}$ do que para o $\mathrm{Cl}$. As raízes tendem a manter convenientemente constante os níveis de $\mathrm{Na}^{+} \mathrm{e} \mathrm{Cl}$ ao longo do tempo de exposição ao estresse, por meio da exportação desses íons para o solo ou parte aérea.

Não houve efeito significativo dos tratamentos aplicados para a área foliar, matéria seca do caule e matéria seca das folhas (Tabela 3).

Tabela 3. Resumo de análise de variância para a área foliar (AF), matéria seca das folhas (MSF) e matéria seca do caule + ramos (MSC) de plantas do clone CCP 06 de cajueiro anão-precoce após 13 meses de aplicação dos tratamentos com águas de diferentes concentrações salinas

\begin{tabular}{lclcc}
\hline \multirow{2}{*}{ FV } & \multirow{2}{*}{ GL } & \multicolumn{3}{c}{ Quadrados médios } \\
\cline { 3 - 5 } & & $\left.\mathbf{A F} \mathbf{~ ( m}^{2}\right)$ & $\mathbf{M S F}\left(\mathbf{m g ~ g}^{-1} \mathbf{M S}\right)$ & $\left.\mathbf{M S C} \mathbf{~ ( m g ~ g ~}^{-1} \mathbf{M S}\right)$ \\
Blocos & 2 & $1,533 \mathrm{~ns}$ & $25.194,802 \mathrm{~ns}$ & $422.694,5422^{*}$ \\
Tratamentos & 4 & $0,685 \mathrm{~ns}$ & $9.369,108 \mathrm{~ns}$ & $68.873,484 \mathrm{~ns}$ \\
Resíduo & 8 & 0,806 & $9.586,91$ & $57.006,5$ \\
Média & & 3,36 & 411,46 & $1.496,55$ \\
CV (\%) & & 26,71 & 23,80 & 15,95 \\
\hline
\end{tabular}

*, ${ }^{\star *}$ : significativo a nivel de 0,05 e 0,01 de probabilidade, respectivamente, pelo teste $\mathrm{F}$; ns: não significativo.

A média obtida para a variável de área foliar foi de 3,36 $\mathrm{m}^{2}$. A média de matéria seca da folha foi de aproximadamente $411 \mathrm{~g}$, enquanto a matéria seca do caule + ramos foi de 1.496 g. Esses resultados são decorrentes da não existência de diferenças estatísticas entre os níveis de salinidade para as variáveis de taxa fotossintética e crescimento das plantas (dados não apresentados), uma vez que uma redução na fotossíntese impactaria o crescimento foliar e por sua vez a redução na área foliar faria com que ocorresse diminuição na área de captação de energia luminosa, bem como na fixação de $\mathrm{CO}_{2}$ por unidade de área (Marschner, 1995).

É sabido que sob condições de estresse salino as plantas utilizam estratégias bioquímicas que incluem acumulação ou exclusão seletiva de íons, controle de entrada de íons pelas raízes e transporte para as folhas, compartimentalização de íons a nível celular (vacúolos) e estrutural (folhas), entre outros (Esteves \& Suzuki, 2008).

Plantas tolerantes à salinidade frequentemente também desenvolvem ajustamento osmótico, contribuindo para a manutenção da absorção de água e turgescência celular, garantindo processos fisiológicos vitais, como a abertura estomática, fotossíntese e expansão celular (Sakamoto \& Murata, 2002).

Como o acúmulo de $\mathrm{Na}^{+}$e $\mathrm{Cl}^{-}$nas folhas em função da salinidade da água de irrigação não provocou sintomas de toxidez na cultura, as plantas podem ter sido eficientes em compartimentalizar esses sais no vacúolo e/ou foram capazes de desenvolver ajustamento osmótico para a manutenção da turgescência celular e posterior crescimento, especialmente para o caso do $\mathrm{Na}^{+}$. 
Diferentemente do que aconteceu neste experimento, Bezerra (2001) e Sousa (2011) observaram em plantas nos estádios iniciais de desenvolvimento, que a produção de matéria seca da parte aérea e a área foliar do cajueiro anão-precoce foram afetadas negativamente pela salinidade. Além do estádio de desenvolvimento das plantas, este efeito parece depender ainda da forma de aplicação, uma vez que no presente experimento, a irrigação com água salina, realizada por microaspersores, durante 13 meses não provocou toxidez nas plantas adultas do cajueiro.

\section{Conclusões}

1. A salinidade provocou aumento no acúmulo de sódio nos caules, raízes e folhas, enquanto os teores de cloreto praticamente não foram alterados.

2. Os maiores acúmulos de sódio e cloreto, em função da salinidade, ocorreram nas folhas, seguido das raízes absorventes, com os menores teores nas raízes de sustentação e no caule.

3. O crescimento do cajueiro, clone CCP 06 , não foi afetado pela irrigação com água salina de até $6,0 \mathrm{dS} \mathrm{m}^{-1}$.

\section{Agradecimentos}

À Embrapa Agroindústria Tropical (EMBRAPA/CNPAT), ao Instituto Nacional de Ciência e Tecnologia em Salinidade (INCTSal), à Fundação Cearense de Apoio ao Desenvolvimento Científico e Tecnológico (FUNCAP) e à Universidade Federal do Ceará (UFC).

\section{Literatura Citada}

Aguiar, M. de J. N., Barreto Junior, J. H. C., Lima, M. W. de. Dados climatológicos: Estação de Pacajus, 2003. Fortaleza: Embrapa Agroindústria Tropical, 2004. 16p. Documentos, 85

Bezerra, I. L. Produção de mudas enxertadas de cajueiro anãoprecoce, usando águas de diferentes salinidades. Campina Grande: UFPB. 2001. 85p. Dissertação Mestrado

Cavalcanti Junior, A. T.; Matos, N. N.; Silveira, J. A. G. Comportamento estomático do porta-enxerto CCP-06 e da muda enxertada CCP 76/06, submetidos aos estresses hídrico e salino. 1.ed. Fortaleza: Embrapa Agroindústria Tropical, 2003. 16p.

Crisóstomo, L. A.; Santos, F. J. de; Oliveira, V. H. de; Raij, B. V.; Bernardi, A. C. de C.; Silva, C. A.; Soares, I. Cultivo do cajueiro anão-precoce: Aspectos fitotécnicos com ênfase na adubação e na irrigação. Fortaleza: Embrapa CNPAT, 2003. 8p. Circular Técnica, 8

Esteves, B. S.; Suzuki, M. S. Efeito da salinidade sobre as plantas. Oecologia Brasiliensis, v.12, p.30-40, 2008.

FAO - Food and Agriculture Organization of the United Nations. Water in agriculture: opportunity untapped. Rome: FAO. 2006.
Ferreira, R. G.; Távora, F. J. A. F.; Hernandez, F. F. F. Distribuição da matéria seca e composição química das raízes, caule e folhas da goiabeira submetida a estresse salino. Pesquisa Agropecuária Brasileira, v.36, p.79-88, 2001.

Gaines, T. P.; Parker, M. B.; Gascho, G. J. Automated determination of chlorides in soil and plant tissue by sodium nitrate. Agronomy Journal, v.76, p.371-374, 1984.

Gheyi, H. R.; Correia, K.G.; Fernandes, P. D. Salinidade do solo e crescimento e desenvolvimento das plantas. In: Nogueira, R. J. C.; Araújo, E. L.; Willadino, L. G.; Cavalcante, U. M. T. (ed) Estresses ambientais: Danos e benefícios em plantas. Recife: UFRPE: Imprensa Universitária, 2005, p.95-105.

Greenway, H.; Osmond, C. Salt response of enzymes from species differing in salt tolerance. Plant Physiology, v.49, p.256-259, 1972.

Malavolta, E.; Vitti, G. C.; Oliveira, S. A de. Avaliação do estado nutricional de plantas: Princípios e aplicações. Piracicaba: Potafos, 1997. 308p.

Marschner, H. Mineral nutrition of higher plants. 2.ed. London: Academic Press, 1995, 889p.

Meloni, D. A.; Gulotta, M. R.; Martínez, C.A.; Oliva, M. A. The effects of salt stress on growth, nitrate reduction and proline and glycine betaine accumulation in Prosopis alba. Revista Brasileira de Fisiologia Vegetal, v.16, p.39-46, 2004.

Prisco, J. T.; Gomes-Filho, E. Fisiologia e bioquímica do estresse salino em plantas. In: Gheyi, H. R.; Dias, N. da S.; Lacerda, C. F. de (ed) Manejo da salinidade na agricultura: Estudos básicos e aplicados. Fortaleza: INCTSal, 2010. p.147-164.

Rhoades, J. D.; Kandiah, A.; Mashali, A. M. The use saline waters for crop production. Rome: FAO. 1992. 133p.

Sakamoto, A.; Murata, N. The role of glycine betaine in the protection of plants from stress: clues from transgenic plants. Plant, Cell and Environment, v.25, p.163-171, 2002.

Silva, M.O.; Freire, M.B.G.S.; Mendes, A.M.S.; Freire, F.J.; Sousa, C.E.S.; Góes, G.B. Crescimento de meloeiro e acúmulo de nutrientes na planta sob irrigação com águas salinas. Revista Brasileira de Engenharia Agrícola e Ambiental, v.12, p.593605, 2008.

Soares, A. M. S.; Machado, O. L. T. Defesa de plantas: Sinalização química e espécies reativas de oxigênio. Revista Trópica Ciências Agrárias e Biológicas, v.1, p.9-19, 2007.

Sousa, A. B. O. de. Germinação e desenvolvimento inicial de plântulas de cajueiro anão-precoce sob irrigação salina. Fortaleza: UFC. 2011. 60p. Dissertação Mestrado

Willadino, L.; Camara, T. R. Tolerância das plantas à salinidade: Aspectos fisiológicos e bioquímicos. Enciclopédia biosfera, v.6, p.1-23, 2010.

Wyn Jones, R. Cytoplasmic potassium homeostasis: review of the evidence and its implications. In: Oosterhuis, D.; Berkowitz, G. (ed.). Frontiers in potassium nutrition: New perspectives on the effects of potassium on physiology of plants. Saskatoon: Potash and Phosphate Institute of Canada, 1999. p.13-22. 